\title{
(4R
}

\section{A Case of Hirudiniasis with Upper Gastrointestinal Bleeding} Üst Gastrointestinal Kanamalı Hirudiniasis Vakası

\author{
Mahmut Abuhandan', Mustafa Çalık', Nihat Demir ${ }^{3}$ Ali Ayçiçek ${ }^{4}$ \\ 'Harran Üniversitesi Tıp Fakültesi, Çocuk Sag̃lıg̃ı ve Hastalıkları Anabilim Dalı, Șanlıurfa, Türkiye \\ ${ }^{2}$ Harran Üniversitesi Tıp Fakültesi, Pediatrik Nöroloji Ünitesi Anabilim Dalı, Sanlıurfa, Türkiye \\ ${ }^{3}$ Özel Ufuk Tıp Merkezi, Șanlıurfa, Türkiye \\ ${ }^{4}$ Harran Üniversitesi Tıp Fakültesi, Pediatrik Hematoloji Ünitesi Anabilim Dalı, Şanlıurfa, Türkiye
}

\section{ABSTRACT}

Leech infestations can lead to several symptoms, including epistaxis, hemoptysis, hematemesis, vaginal bleeding and anemia. A five-year-old male patient presented to the emergency ward with bilateral bleeding from the nose in the form of leakage with a duration of one month, as well as bloody vomiting and blood in the sputum for two days prior to admission. The patient was pale, the nose and oropharyngeal mucosa were pale with fresh leakagetype bleeding and there was a similar clot in the nasopharynx. Laboratory examinations were normal. Examination of the oropharynx and nasopharynx was repeated to assess for active bleeding, and a leech $4 \times 1 \mathrm{~cm}$ in size was found in addition to a clot. The leech was detached from the mucosa following administration of a hypertonic saline solution and removed with forceps. Leech infestation should be considered in cases of bleeding and anemia of unknown etiology in patients from rural areas.

Keywords: Hirudiniasis, gastrointestinal bleeding, child, epistaxis Received: 02.05.2011 Accepted: 11.06.2011

\section{ÖZET}

Sülük enfestasyonları epistaksis, hemoptizi, hematemez, vajinal kanama ve anemi gibi semptomlara sebep olabilir. Beș yașında erkek hasta acile 1 aydan beri burundan çift taraflı sızıntı șeklinde kanama ve 2 gündür kanlı kusma șikayeti ile getirildi. Hasta soluk, burun ve orofarinkste sızıntı șeklinde taze kanama ile birlikte farinkste pıhtı olarak deg̃erlendirilen görünüm izlendi. Laboratuar tetkikleri normal olan hastanın aktif kanamanın kontrolü için yapılan tekrarlı orofarinks ve nazofarinks fizik incelenmesinde pıht benzeri görünümün $4 \times 1 \mathrm{~cm}$ boyutlarında sülük oldug̃u kanaatine varıldı. Hipertonik saline solüsyonu verilerek mukozadan ayrıștırılarak çıkarıldı. Kırsal kesimden gelen hastalarda sebebi açıklanamayan kanama ve anemi tablolarında sülük enfestasyonu akla getirilmelidir.

Anahtar Kelimeler: Hirudiniasis, gastrointestinal kanama, çocuk, epistaksis

Geliş Tarihi: 02.05.2011 Kabul Tarihi: 11.06.2011

\section{Giriş}

Sülükler eski çag̃lardan beri bilinen ve ölümcül komplikasyonlara neden olabilen endoparazitlerdir (1, 2). Nazofarinkse yerleștig̃inde, juvenil nazofaringeal anjifibroma veya nazal polip benzeri nazofaringeal neoplazma semptomlarını gösterirler (2). Salgıladıg̃ı histamin benzeri maddeler kapiller damarların kapanmasını engelleyerek devamlı kanamalara neden olabilirler. Kollajen platelet etkileșimiyle birlikte sülüklerin kan çekme sırasında salgılanan proteaz ve dig̃er enzimlerle damar duvarında yaptıkları deg̃ișiklikler kanamanın uzamasına neden olabilirler $(3,4)$. Sülükler mukozal bir yüzeye yapıștıklarında uzun süre kan emilimine bag̃lı olarak hastalarda bazen derin bir anemiye sebep olabilirler (5). Bu yazıda, sülüg̃e bag̃lı hemoptizi, epistaksis ve derin anemi ile gelen ve tanı konulmada güçlük çekilen bir çocuk olguyu literatür ıșig̃ında irdelemeyi amaçladık.

\section{Olgu Sunumu}

Kırsal kesimde oturan, kuyu suyu kullanan beș yașında erkek hasta acile 1 aydan beri burundan çift taraflı sızıntı șeklinde kanama, 2 gündür kanlı kusma ve tükürügüünde taze kan gelme șikayeti ile getirildi. Fizik muayenesinde; şuur açık, soluk görünümde burun ve orofarinkste sızıntı șeklinde taze kanama ile birlikte farinkste pıhtı olarak deg̃erlendirilen görünüm izlendi. Kan basıncı 90/65 mmHg, nabız 136/dk, solunum 32/dk idi. Sistem muayeneleri normal, batın ultrasonografisinde patolojik bulgu saptan- 
madı. Kan tetkiklerinde; kanama zamanı (KZ):2/dk, pıhtılașma zamanı (PZ): 3/dk, aPT: 24.5sn, PT: 12.5sn, Hct: \%22.8, Hb: 7.4g/dL, PLT: 466000/mL, beyaz küre: 1300/mm³ $\mathrm{mCV}^{3} 77.6$ fL, MCH: 24.6pg, AST: 17U/L, ALT: 13U/L, LDH: 216U/L saptandı. Aktif kanamanın kontrolü için yapılan tekrarlı orofarinks ve nazofarinks muayanesinde pıhtı benzeri görünümün $4 \times 1 \mathrm{~cm}$ boyutlarında sülük oldug̃u kanaatine varıldı. Hipertonik saline solüsyonu verilerek mukozadan ayrıștırılarak bir pens yardımıyla çıkarıldı (Resim 1). Kanama sülük çıkarıldıktan 1 saat sonra spontan durdu.

\section{Tartışma}

Sülükler, Annelida kökünde Hirudinea sınıfına bag̃lı, çog̃unlug̃u ılık su göllerinde ve ılıman akarsularda paraziter veya serbest yașam süren, $8 \mathrm{~mm}$ ile $76 \mathrm{~cm}$ arasında farklı uzunluklarda olabilen solucanlardır (6). Genç iken et yedikleri halde, erișkin șekle gelince kanla beslenirler. İnsan ve evcil hayvanlardan birisine rast gelmezse kurbag̃a, balık gibi hayvana hücum ederek öldürünceye kadar kanını emerler. Bir çok bakteri ve paraziti tașırlar $(7,8)$. Suda yașayan sülüklerin zayıf ve güçsüz çeneleri vardır. Bunlar beslenmeleri için üst sindirim sistemi borusu gibi yumușak bir dokuya gereksinim duyarlar. Suda yașayan sülükler genellikle su içerken veya yıkanırken ag̃ız ve burundan girebilir. Aynı zamanda bulaștıg̃ı sularda banyo yapan insanların vulva, vagen, üretralarından saldırabilirler. Ag̃ız ve burundan geçenler nazofarinkse, epiglottise, özefagusa hatta trakea ve bronșlara kadar gelebilirler (9). Sularla ag̃ız, farinks, tonsillere, yemek borusuna ve burun arkasına giderler, günlerce ve hatta haftalarca kalabilirler. Farinkse veya larinkse giren sülükler trakeaya veya bronșlara geçerek ölüme sebep olabilirler ag̃ız ve burundan kan gelmesine sebep olurlar $(7,10)$. Sülük salgısı pıhtılașma sürecinde etkili trombini inhibe eden hirudin içerir. Ayrıca salgıladıg̃ı histamin benzeri maddeler kapiller damarların kapanmasını engelleyerek devamlı kanamalara neden olabilirler. Kollajen platelet etkileșimiyle birlikte sülüklerin kan çekme sırasında salgılanan proteaz ve dig̃er enzimlerle damar duvarında yaptıkları deg̃ișiklikler kanamanın uzamasına neden olabilir $(3,11)$. Olgumuzda bir aydır devam eden burun ve ag̃ıdan kan gelme șikâyetleri vardı.

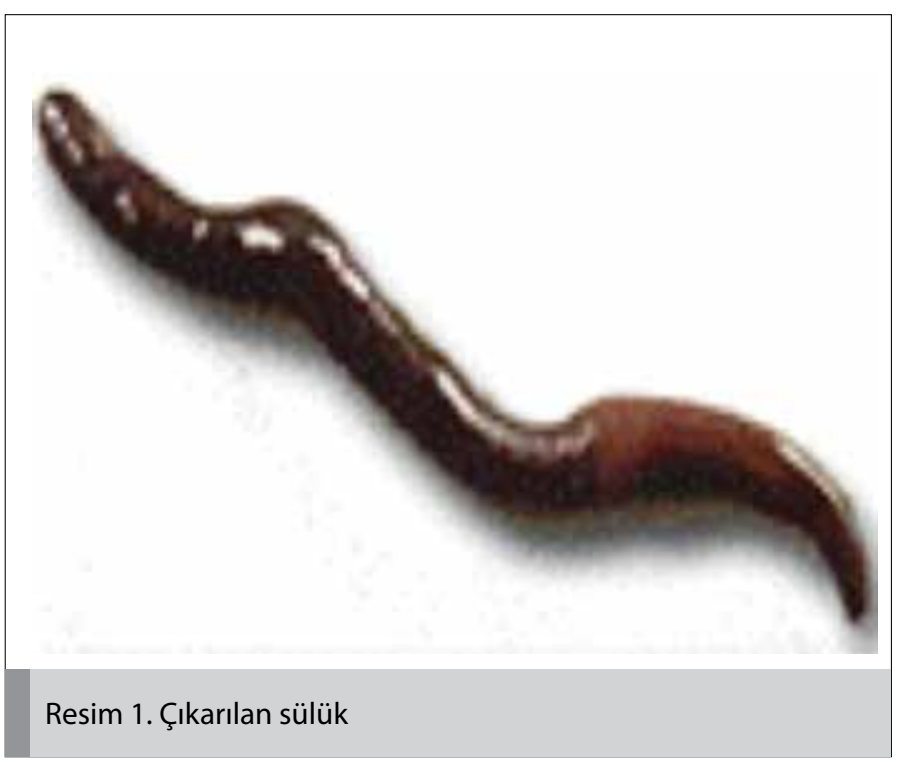

Mukoza membranlarına tutunduklarında ortalama ag̃ırlıklarının 10 katı kadar kan çekebilme özellig̃ine sahiptirler (3). Bundan dolayı suda yașayan sülükler kara sülüklerden daha tehlikelidirler. Çünkü onlar kan transfüzyonu gerektirecek kadar șiddetli anemiye neden olurlar $(12,13)$. Sülüg̃ün üst solunum yoluna yerleșmesi oldukça nadirdir $(8,13)$. En yaygın görülen enfestasyon nazal yerleșimidir (9). Olgumuzda sülük orofarinkse yerleșmiști.

Sülük güçlü bir șekilde emici ag̃zı ile tutundug̃undan, kolay rüptüre olabilen ve kaygan vücut yüzeyinden dolayı, onu tutundug̃u yerden çıkarmak kolay deg̃ildir (14). Olgumuzda, nazofarinkse yerleșen sülük hipertonik saline solüsyonu verilerek mukozadan ayrıștırılarak, bir pens yardımıyla çıkarıldı (15).

\section{Sonuç}

Kaynak suyu dezenfeksiyonu ve sanitasyonu yapılmayan kırsal kesimlerde yașayanlarda sebebi bulunamayan epistaksis, hemoptizi ve anemi durumlarında sülük enfestasyonu akılda tutulmalıdır.

\section{Çıkar çatışması}

Yazarlar herhangi bir çıkar çatıșması bildirmemișlerdir.

\section{Kaynaklar}

1. Munshi Y, Ara I, Rafique H, Ahmad Z. Leeching in the history--a review. Pak J Biol Sci 2008; 11: 1650-3. [CrossRef]

2. Dalil-Tojari A. Foreign bodies of the tracheobroncial tree and esophagus. Acta Med Iran 1975; 18: 155-60.

3. Kavaklı HȘ, Tanrıverdi F. Hirudoterapiye bag̃lı gelișen bilateral hemartroz: olgu sunumu. JAEMCR 2010; 2: 20-2.

4. Kraemer BA, Korber KE, Aquino TI, Engleman A. Use of leeches in plastic and reconstructive surgery: a review. J Reconstr Microsurg 1988; 4: 381-6. [CrossRef]

5. Kruger $\mathrm{C}$, Malleyeck I, Olsen $\mathrm{OH}$. Aquatic leech infestation: a rare cause of severe anemia in an adolescent Tanzanian girl. Eur J Pediat 2004; 163: 297-9. [CrossRef]

6. Gönenç B. Sülüklerin genel özellikleri, patojenite ve tedavi șekilleri. Kafkas Ünv Vet Fak Derg 2000; 6: 137-44.

7. Unat E, Yücel K, Samastı M. Unat'ın Tıp Parazitolojisi, 1991; 162: 247-51.

8. Labadi MH, Jamal MN. Leeches in the larynx. J Laryngol Otol 1997; 111: 980-1. [CrossRef]

9. Gülog̃lu C, Al B, Özhasenekler A, Gülü N, Aldemir M. Üst solunum yolu obstruksiyonu, burun kanaması ve kronik aneminin nadir bir sebebi olarak sülük. Tıp Araștırmalar Dergisi 2004; 2: 45-8.

10. Pandey CK, Sharma R, Baronia A, Agarwal A, Singh N. An unusual vause of respiratory distress: live leech in the larynx. Anesth Analg 2000; 90: 1227-8. [CrossRef]

11. George JR: Parasitology for Veterinarians. Third Ed. Thedorides VJWB Saunders Company. Philadelphia. 1980.

12. el-Awad ME, Patil K. Haematemesis due to leech infestation. Ann Trop Paediatr 1990; 10: 61-2.

13. White GB. Leeehes and leech infestation in Cook GC (ed), Manson's Tropical Disseases 20th ed, Saunders London, 1998. (p. 1523-25).

14. Struyvenberg PA, Van Boxel FA, Polderman AM. A leech as an unusual cause of epistaksis. Ned Tijdschr Geneeskd 1986; 130: 791-2.

15. İkizceli I, Avșarog̃ulları L,Sözüer E, Yürümez Y, Akdur O. Bleeding due to a medicinal leech bite. Emerg Med J 2005; 22: 458-60. [CrossRef] 